\title{
Using Nanomedicine to Drive Advances in Cancer Immunotherapy: A Mini Review
}

\author{
Ghizlane Choukrani ${ }^{1,2}$, Jimena Álvarez Freile ${ }^{1,2}$, Edwin Bremer ${ }^{2}$ and Lars Dähne ${ }^{1 *}$ \\ ${ }^{1}$ Surflay Nanotec GmbH, Germany \\ ${ }^{2}$ Department of Haematology, University Medical Center Groningen, University of Groningen, The Netherlands
}

*Corresponding author: Lars Dähne, Surflay Nanotec GmbH, Max-Planck-Str.3, 12489 Berlin, Tel: 0049-30-63921764 Germany.

To Cite This Article: Lars Dähne, Using Nanomedicine to Drive Advances in Cancer Immunotherapy: A Mini Review. 2020 - 8(2). AJBSR. MS.ID.00128. DOI: 10.34297/AJBSR.2020.08.001248.

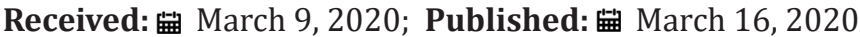

\begin{abstract}
Immunotherapy has shown remarkable clinical success and holds tremendous promise for enhancing cancer treatment Outcome. However, therapeutic complete responses are limited to a subset of patients selected cancers and treatment outcome can trigger severe toxicity due to systemic activation of the immune system. Here, we discuss the opportunities to overcome these drawbacks by combining immunotherapy with nanomedicine using tailor-made nanoparticles (NPs) to increase cancer selectivity and minimize toxicity. Further, we provide directions on requirements and discuss advantageous characteristics of using calcium carbonate as core component of such NPs.
\end{abstract}

Keywords: Nanoparticles, Cancer Immunotherapy, Drug delivery

\section{Mini Review}

In recent years, immunotherapy with so-called checkpoint inhibitors that (re)activate tumour-directed $\mathrm{T}$ cell responses has induced complete remissions in a subset of patients, conclusively demonstrating the significant potential of immunotherapy in cancer $[1,2]$. One of the major challenges for such immunotherapy is the ubiquitous immune-related side-effects and limited intrinsic selectivity for cancer [3]. This challenge is starting to be addressed by an emerging field of research that combines immunotherapy with nanotechnological design of tailored carrier materials. Hereby, systemic exposure of active therapeutics is prevented and accumulation as well as selective release of immunotherapeutics in so-called tumour micro-environment is achieved. Due to their unique properties, nanoparticles accumulate selectively at the tumor by the so-called enhanced permeability and retention effect (EPR). Their surface can be modified to increase their blood circulation time by a stealth effect and to actively target the tumor micro-environment with precision, increasing both safety and therapeutic efficacy [4].

Various articles providing proof of concept for this use of NPs have emerged in recent years. For instance, Li Tang et al. used pro tein nanogels (NGs) to selectively deliver and release supporting protein drug (i.e IL- 2 and TGF- $\beta$ receptor-I inhibitor) on $\mathrm{T}$ cells in response to $\mathrm{T}$ cell receptor activation at 8-fold higher doses of administered cytokines, without toxicity and a 16-fold expansion of $\mathrm{T}$ cells in tumors. Several other nanoparticle designs have been developed for cancer immunotherapy applications, of which some key examples are summarized in Table 1. However, there are still major challenges associated with the design of these delivery systems, such as sub-optimal drug-loading. Further, a lack of regulation of drug release, which is often mediated by spontaneous leakage from the nanoparticles. In addition, degradation, undesired release or chemical modification of the loaded molecules during storage or blood circulation requires new design of nanoparticles-based drug delivery systems that can address these challenges.

The first consideration when choosing the NP type is its ability to achieve high loading of the immunotherapeutics without altering their biological properties and. Ideally, degradable NPs at the site of the tumor. Porous templates with tuneable parameters including pore size, pore volume have gained considerable attention due to 
their large surface area and the ability to load different sizes of molecules [5]. There are several candidate materials known. E.g. mesoporous silica (MPS) has been most intensively investigated due to its stable and rigid framework with excellent chemical, thermal and mechanical stability. The biomolecules are loaded to the particle's pores, which are then modified with a 'gatekeeper' that responds to an internal or external stimulus such as $\mathrm{pH}$ [6], redox reaction [7], temperature [8] and antibodies [9]. However, silica cannot be exploited directly for controlled drug delivery and further modifications are required making an approval by the FDA difficult.

Another potential candidate for therapeutic biomolecule delivery is vaterite, a polymorph of calcium carbonate (CaCO3), which is formed by the direct mixing of soluble salts containing $\mathrm{Ca} 2+$ and C032-. Vaterite has been gaining increasing popularity due to its low cost, biocompatibility and high porosity, which enables efficient protein encapsulation. Perhaps most importantly, vaterite is $\mathrm{pH}$ sensitive, an intrinsic feature that may allow for selective drug release in the acidic tumor micro-environment due to its selective dissolution [10]. Vaterite particles can also be produced in a precisely defined size, ranging from several micrometres to a few hundred nanometres. Particles and their pore size strongly depend on the experimental conditions such as salt type used, their concentration, $\mathrm{pH}$, temperature, mixing rate and the agitation intensity of the reaction mixture. Controlling these various parameters enables the synthesis with defined vaterite particles of small size dispersion. Herewith, one can for instance tailor the size of NPs to meet specific needs, e.g. for optimal passive tumor targeting using the EPR effect [10-12], or tailor pore size to meet loading needs [13].

Another important consideration for immunotherapeutic NPs is the loading strategy of the biomolecule. This step should be carefully chosen to achieve optimal loading, while at the same retaining bioactivity. Biomolecules can be loaded to vaterite either by physical adsorption/pore diffusion or by coprecipitation. In the first strategy, $\mathrm{pH}$ is a decisive factor of the loading efficiency when dealing with charged macromolecules, whereas for uncharged macromolecules the molecular weight is a crucial factor [14]. The second loading approach is coprecipitation, and it is based on the inclusion of the biomolecules inside vaterite particles during the process of growth from the mixture of aqueous salt solutions. This strategy typically leads to a higher loading efficiency, e.g. with a 5-fold increase in loading for coprecipitation compared to physical absorption using alpha-chymotrypsin [15]. Achieving high protein loading to a particulate delivery system is advantageous for drug delivery, but it is also crucial to preserve the activity of the biotherapeutic upon encapsulation. This step presents a major challenge when formulation conditions are far away from the physiological environment. Biomolecules such as proteins are most stable and have maximum activity at their optimum $\mathrm{pH}$, but stability and activity decreases as the $\mathrm{pH}$ value incrementally increases/decreases from this value. In this respect, alpha-chymotrypsin retained $56 \%$ activity by adsorption into synthesized vaterite particle at $\mathrm{pH}$ 5.0. Conversely, residual activity was only $12 \%$ when encapsulation was performed via the coprecipitation process. This lower activity might be due to the high $\mathrm{pH}$ of sodium carbonate during synthesis. Therefore, when attempting coprecipitation, it is pivotal to choose solutions and salts that has a $\mathrm{pH}$ in the activity range of the therapeutic molecule during the process. Rational selection of salts e.g. sodium hydrogen carbonate, calcium chloride, $\mathrm{CaCl}_{2}$, or calcium nitrate, $\mathrm{Ca}\left(\mathrm{NO}_{3}\right)_{2}$ can be used for achieving reaction conditions close to physiological once [16-21].

Although many technical challenges are faced in nanoparticle design for immunotherapy, of which we here have discussed the choice and design of the nanoparticle, the future of these 'magic bullets' continues to expand. Indeed, exciting proof-of-concept studies highlight the promise of combining immunotherapy with nanomedicine. The next few years are expected to provide substantial breakthroughs and insight into a new era of next-generation immunotherapy (Table 1).

\begin{tabular}{|c|c|c|c|}
\hline Nano particle & Mechanism & Outcome & Citation \\
\hline PLGA & Deliver TSP to APCs and improve the efficacy of $\alpha \mathrm{PD}-1$ treatment. & $\begin{array}{l}20 \% \text { cure rate compared with } 0 \% \text { without } \\
\text { nanoparticles system }\end{array}$ & 17 \\
\hline IONPs & $\begin{array}{l}\text { Stimulate a tumors specific CD8+ cytotoxic T cell response by } \\
\text { Hsp70-SPIONs }\end{array}$ & $\begin{array}{l}\text { Delayed tumor progression and an increased } \\
\text { overall survival. }\end{array}$ & 18 \\
\hline Zinc Oxide & Carcinoembryonic antigen delivery into dendritic cells & Delayed tumour growth enhanced survival. & 19 \\
\hline Liposome & immune cell-recruiting liposomal system (FN-nps) & Assisting anti-PD-1 antibody immunotherapy & 20 \\
\hline LPG & $\begin{array}{l}\text { Liposomal polymeric gels of drug-complexed cyclodextrins and } \\
\text { cytokine-encapsulating biodegradable polymers }\end{array}$ & $\begin{array}{l}\text { Increased activity of NK and intratumoral-acti- } \\
\text { vated CD8+ T-cell infiltration }\end{array}$ & 21 \\
\hline
\end{tabular}

PLGA: Poly Lactic-co-Glycolic Acid, TSP: Tumour-Specific Proteins, APCs: Antigen-Presenting Cells, IONPs: Iron Oxide Nanoparticles, LPG: Liposomal Polymeric Gel

The work was supported by the European Commission under GA number 813871 — I-Direct. 


\section{References}

1. Maude SL, Frey N, Shaw PA, Plenc R, Barrett DM, et al. (2014) Chimeric antigen receptor $\mathrm{T}$ cells for sustained remissions in leukemia. New England Journal of Medicine 37116): 1507-1517.

2. Gettinger SN, Horn L, Gandhi L, Spigel DR, Antonia SJ, et al. (2015) Overall survival and long-term safety of nivolumab (anti-programmed death 1 antibody, BMS-936558, ONO-4538) in patients with previously treated advanced non-small-cell lung cancer. Journal of clinical oncology 2015, 33 18):2004-2012.

3. Kennedy LB, Salama AKS (2020) A review of cancer immunotherapy toxicity. CA Cancer J Clin 2020.

4. Shao K, Singha S, Clemente-Casares X, Tsai S, Yang Y, et al. (2015) Nanoparticle-based immunotherapy for cancer. ACS Nano 9 1): 16-30.

5. Baeza A, Ruiz-Molina D, Vallet-Regí M (2017) Recent advances in porous nanoparticles for drug delivery in antitumoral applications: inorganic nanoparticles and nanoscale metal-organic frameworks. Expert opinion on drug delivery 14 6): 783-796.

6. Chen T, Wu W, Xiao H, Chen Y, Chen M, et al. (2016) Intelligent drug delivery system based on mesoporous silica nanoparticles coated with an ultra-pH-sensitive gatekeeper and poly (ethylene glycol). ACS Macro Letters 5 1): 55-58.

7. Wang Y, Han N, Zhao Q, Bai L, Li J, et al. (2015) Redox-responsive mesoporous silica as carriers for controlled drug delivery: a comparative study based on silica and PEG gatekeepers. European Journal of Pharmaceutical Sciences 72: 12-20.

8. Liu J, Detrembleur C, De Pauw-Gillet MC, Mornet S, Vander Elst L, et al. (2014) Heat-triggered drug release systems based on mesoporous silica nanoparticles filled with a maghemite core and phase-change molecules as gatekeepers. Journal of Materials Chemistry B 2(1): 59-70.

9. Climent E, Bernardos A, Martinez-Manez R, Maquieira A, Marcos MD, et al. (2009) Controlled delivery systems using antibody-capped mesoporous nanocontainers. J Am Chem Soc. 131(39): 14075-14080.

10. Ueno Y, Futagawa H, Takagi Y, Ueno A, Mizushima Y (2005) Drugincorporating calcium carbonate nanoparticles for a new delivery system. Journal of Controlled Release 103 (1): 93-98.

11. Parakhonskiy BV, Haase A, Antolini R, (2012) Sub-micrometer vaterite containers: synthesis, substance loading, and release. Angew Chem Int Ed Engl 51 (5): 1195-1197.
12. Svenskaya YI, Fattah H, Inozemtseva OA, Ivanova AG, Shtykov SN, et al. (2018) Key parameters for size-and shape-controlled synthesis of vaterite particles. Crystal Growth \& Design 18 (1): 331-337.

13. Feoktistova N, Rose J, Prokopović VZ, Vikulina AS, Skirtach, A, et al. (2016) Controlling the vaterite CaCO3 crystal pores. Design of tailormade polymer-based microcapsules by hard templating. Langmuir 32 (17): 4229-4238.

14. Sukhorukov GB, Volodkin DV, Günther AM, Petrov AI, Shenoy DB, et al. (2004) Porous calcium carbonate microparticles as templates for encapsulation of bioactive compounds. Journal of Materials Chemistry 14 (14): 2073-2081.

15. Petrov AI, Volodkin DV, Sukhorukov GB (2005) Protein-calcium carbonate coprecipitation: a tool for protein encapsulation. Biotechnol Prog 21(3): 918-925.

16. Konopacka-Łyskawa D (2019) Synthesis methods and favorable conditions for spherical vaterite precipitation: a review. Crystals 9 (4): 80-223.

17. Min Y, Roche KC, Tian S, Eblan MJ, McKinnon KP, Caster JM, et al. (2017) Antigen-capturing nanoparticles improve the abscopal effect and cancer immunotherapy. Nature nanotechnology 12(9): 877-882.

18. Shevtsov MA, Nikolaev BP, Yakovleva LY, Parr MA, Marchenko YY, et al. (2015) 70-kDa heat shock protein coated magnetic nanocarriers as a nanovaccine for induction of anti-tumor immune response in experimental glioma. J Control Release. 220(28): 329-340.

19. Cho NH, Cheong TC, Min JH, Wu JH, Lee SJ, et al. (2011) A multifunctional core-shell nanoparticle for dendritic cell-based cancer immunotherapy. Nat Nanotechnol. 6(10): 675-682.

20.Zhou B, Jiang Q, Xiao X, Xu X, Xu Y, et al. (2019) Assisting anti-PD-1 antibody treatment with a liposomal system capable of recruiting immune cells. Nanoscale 11 (16): 7996-8011.

21. Park J, Wrzesinski SH Stern E, Look M, Criscione J, Ragheb R, et al. (2012) Combination delivery of TGF- $\beta$ inhibitor and IL-2 by nanoscale liposomal polymeric gels enhances tumour immunotherapy. Nat Mater 11 (10): 895-905. 